\title{
MENGOPTIMALKAN SELF MANAGEMENT SEBAGAI UPAYA MENUMBUH KEMBANGKAN KEGIATAN PEMBELAJARAN MATA PELAJARAN EKONOMI DI SEKOLAH MENENGAH ATAS
}

\author{
Drs. Adi Suprayitno. M.Pd \\ Guru SMAN 6 Madiun
}

\begin{abstract}
:
Self-Management represent therapy technique form of behavior/behavioral. Therapy form of behavior this focus study to individual to become effective changer this for behavior will own. technique of Self-Management this cover: self-monitoring, self-evaluation, and self-reinforcement. Third the technique aim to be behavioral to to increase learn Senior High School student. Learn SMA beside as instructor, also as coach and counsellor. As counsellor, teacher share to assist process learn by creating the condition of conducive student able to alter its own behavior and also can solve internal issues activity of study economic subject. Problem of which often experienced of to relate to process learn namely student do not want to enquire if/when meeting items which is difficult to be comprehended, and in disregard of student question of items studied. To overcome problems of student, can be developed technique of self-management. Stages;Steps mentioned as following: (1) planning and executing distorting technique; (2) evaluating distorting program.
\end{abstract}

Keyword: self-management, study economic subject, Senior High School student.

\section{PENDAHULUAN}

Self-management (kelola diri) merupakan strategi pengubahan perilaku yang diarahkan sendiri untuk mengelola hidup sendiri secara efektif (Cormier \& Cormier, 2002 : 87). Alberto Troutman (2001 : 34) mengemukakan fokus pendekatan self-management adalah mengajarkan kepada individu untuk menjadi pengubah yang efektif akan perilakunya sendiri. Secara umum kelola diri dapat diajarkan melalui langkahlangkah yang sama ketika seorang guru mengajarkan keterampilan akademis kepada siswanya. Kanfer (2003 : 56) mengemukakan bahwa self-management memiliki tiga teknik yaitu self-monitoring, selfevaluation, dan self-reinforcement.

Kaitannya dengan bimbingan, self-management merupakan bentuk terapi behavior (Corey, 2000 : 67). Terapi behavior merupakan proses bantuan yang diberikan kepada individu untuk belajar memecahkan masalah interpersonal, emosional, dan pengambilan keputusan tertentu (Krumboltz dan Toresen dalam Shertzer, 2004: 199). Sebagai pembimbing, guru berperan membantu proses belajar dengan menciptakan kondisi yang sedemikian rupa sehingga siswa dapat mengubah perilaku sendiri dalam memecahkan masalah belajar (Corey, 2000 : 121). Guru SMA adalah guru 
mata pelajaran yang memiliki kompetensi sesuai yang diemban guru, disamping sebagai pengajar, juga mempunyai tugas sebagai pembimbing, serta melatih siswa

Masalah yang sering muncul pada diri siswa Sekolah Menengah Atas, adalah berkaitan dengan proses belajar, diantaranya perilaku pasif pada saat proses pembelajaran, ia tidak mau bertanya atau menanggapi pertanyaan dari materi yang sedang dibahas. Ketidakmauan bertanya atau menanggapi pertanyaan baik dari guru maupun temannya disebabkan oleh kekurangpercayaan diri siswa terhadap kemampuan yang dimiliki. Dan tidak menutup kemungkinan faktor situasi kelas ikut mendukung. Yang biasa terjadi di lapangan, bila ada temannya yang bertanya, teman lainnya bilang "huuuu...", dan tidak jarang masih ditertawakan. Yang lebih fatal lagi bila ada guru yang tidak senang bahkan marah, bila ditanya tentang materi oleh siswanya. Atas dasar tersebut, perlu adanya bimbingan agar siswa dapat meningkatkan keaktifan dalam proses belajarnya.

Situasi kelas yang demikian menjadikan siswa pasif dalam kegiatan pembelajaran, meskipun mereka tidak paham terhadap materi yang dibahas. Atas dasar itu, maka guru sebagai pengelola kelas mempunyai kewajiban untuk dapat menciptakan kondisi yang memungkinkan semua siswa aktif dalam proses pembelajaran, diantaranya aktif menanggapi materi yang dibahas baik mengajukan pertanyaan maupun menjawab pertanyaan. dengan baik, sehingga hasil belajar dapat meningkat. Atas dasar tersebut, perlu adanya bimbingan agar siswa dapat meningkatkan keaktifan dalam proses belajarnya. Disinilah letak perlunya pengembangan self-manajemen sebagai upaya layanan bimbingan belajar kepada siswa Sekolah Menengah Atas.

Belajar mempunyai keterkaitan dengan latihan. Dalam belajar dan latihan akan terjadi perubahan perilaku. Aspek perilaku yang berubah karena latihan, adalah dalam bentuk skill atau keterampilan. Hal ini dipertegas oleh pendapat Surya (2002 : 52) bahwa belajar akan lebih berhasil apabila disertai dengan latihan-latihan yang teratur dan terarah. Berdasarkan hal tersebut, maka untuk mengaktifkan siswa dalam proses belajar, perlu adanya latihan-latihan untuk memotivasi siswa bertanya atau menanggapi pertanyaan dengan baik.

Sama halnya dengan adanya tahapan pengajaran suatu keterampilan akademis, juga ada rangkaian seluruh kegiatan instruksional yang dapat digunakan untuk mengembangkan selfmanagement. Senada dengan hal tersebut Schloss \& Smith (2004: 29) mengemukakan bahwa beberapa prosedur yang digunakan untuk mengajarkan dengan teknik selfmanagement hampir sama dengan prosedur untuk mengajarkan keterampilan akademis, yaitu ada tujuan, kegiatan, materi, dan penilaian.

Keberhasilan belajar siswa tidak datang secara tiba-tiba, tetapi melalui proses yang panjang, diantaranya membekali siswa suatu pengalaman belajar yang bermakna, dalam bentuk keterampilan untuk dapat mengelola diri dalam belajar. Dengan bekal keterampilan mengelola diri dalam 
belajar dengan baik, diharapkan siswa termotivasi untuk meningkatkan perilaku belajar, sehingga hasil belajar dapat meningkat.

Bimbingan belajar merupakan suatu proses bantuan yang diberikan kepada individu/sekumpulan individu yang diduga akan dan sedang mengalami masalah belajar dengan maksud agar dapat belajar sebaik mungkin sesuai kesanggupan dan kemampuan yang dimilikinya, serta dapat memperoleh kesuksesan dalam proses belajarnya (Abdullah, dkk. 1990: 130). Bimbingan belajar ditujukan kepada semua siswa dengan maksud agar mereka berupaya meningkatkan perilaku belajarnya.

Siswa pada anak usia tersebut, perkembangan kognitifnya dalam taraf berpikir operasional konkret, artinya anak mampu melakukan proses berpikir pada taraf konkret (Piaget dalam Surya, dkk., 2002 : 68). Dalam melaksanakan tugas-tugas belajarnya, anak usia SMA dapat melakukan untuk hal-hal yang bersifat konkret. Dengan demikian, untuk mempelajari konsep-konsep yang dipelajari anak, hendaknya disertai dengan hal-hal yang bersifat konkret. Hal ini dapat dilakukan dengan melalui contoh, latihan, demonstrasi, atau alat peraga konkret. Misalnya untuk memperkenalkan konsep selfmanagement dalam belajar, guru dapat memberikan contoh, demonstrasi, dan latihan-latihan konkret kepada siswa bersamaan dengan kegiatan pembelajaran. Penerapan selfmanagement ini menyatu dengan kegiatan pembelajaran akademik.

Berdasarkan uraian di atas, maka yang menjadi fokus penulisan ini adalah bagaimana mengembangkan program self-management untuk pelayanan bimbingan belajar di Sekolah Menengah Atas.

Tujuan penulisan ini adalah untuk mengembangkan program selfmanagement dalam upaya pelayanan bimbingan belajar di Sekolah Menengah Atas. Disamping itu, membimbing siswa mengatasi permasalahannya sendiri yang berkaitan dengan peningkatan perilaku belajarnya.

Untuk mengembangkan selfmanagement dilakukan dua langkah yaitu: (1) merencanakan dan melaksanakan suatu teknik pengubahan (self-monitoring, self-evaluatiom, dan self-reinforcement); (2) mengevaluasi program pengubahan Teknik SelfMonitoring untuk Meningkatkan Perilaku Belajar Siswa di SMA.

Self- monitoring (pantau diri) didefinisikan sebagai proses memonitor perilaku yang akan dijadikan sasaran, dan juga proses untuk menentukan perilaku yang bagaimana yang diinginkan. Dalam tahap ini, siswa melakukan pengamatan dengan cermat terhadap tingkah lakunya sendiri dan sekaligus melakukan pencatatan hasil pengamatannya. Guru seyogyanya memberikan contoh cara melakukan pencatatan yang baik/praktis dan tidak menyulitkan siswa yang bersangkutan. Bila perlu, berikan latihan konkret pada siswa Sekolah Menengah Atas.

Pencatatan hasil pengamatan ini merupakan kegiatan yang sangat penting untuk melihat perubahan tingkah laku dengan cermat (Corey, 2000 : 45). Hal ini dilakukan untuk menghindarkan adanya kesalahan yang mungkin timbul dari adanya perubahan tingkah laku 
tersebut yang sebenarnya hanya merupakan "harapan" belaka.

Untuk mengajarkan teknik pantau diri, diperlukan persiapan pendahuluan, hal ini berkenaan dengan alat (instrumen) yang akan digunakan siswa untuk mencatat perilakunya.

Ada tiga model (bentuk) instrumen yang dapat dipilih siswa yakni, pencatatan dengan berdasarkan pada frekuensi munculnya perilaku, artinya berapa sering perilaku tersebut muncul. Pada model ini siswa diminta untuk memberikan tanda "+" setiap kali respon (perilaku) yang diharapkan muncul, dan "-_" setiap kali tidak merespon atau tidak berperilaku pada form yang telah disediakan.

Contoh:

Instrumen

berdasarkan Frekuensi

Nama . ....

Kelas

Contoh Perilaku Target:

\section{Mengajukan/Menanggapi Pertanyaan}

\section{Petunjuk!}

1) Berilah tanda " + ", jika Anda sedang mengajukan/menanggapi pertanyaan pada kotak yang disediakan

2) Berilah tanda “ - " , jika Anda sedang tidak mengajukan/menanggapi pertanyaan pada kotak yang disediakan.
3) Waktu yang disediakan $1 \mathrm{X}$ pertemuan (40 menit/ 4 x 10 menit)

4) Ingat, jangan mengisi seluruh kotak pada satu waktu

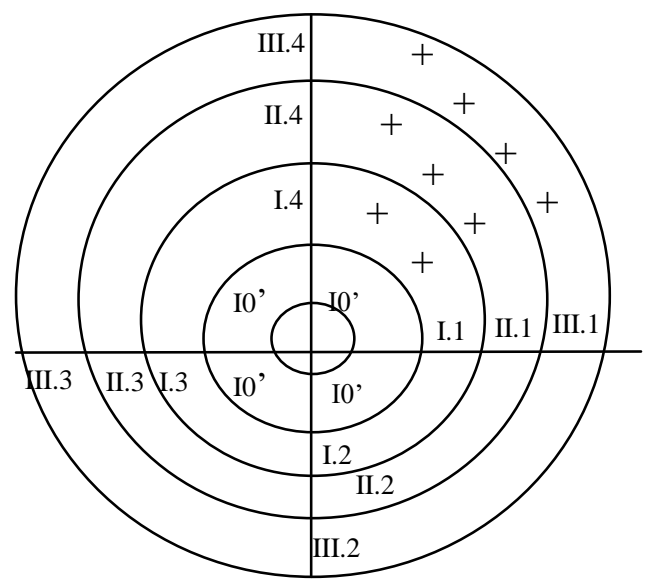

\section{Keterangan:}

I, II, III, IV = Perlakuan ke Hari, tgl.: 10' = per 10 menit-an

Untuk mengevaluasi program ini, penghitungannya adalah berapa sering ia mengajukan atau menanggapi pertanyaan selama waktu yang ditentukan (per 10 menit-an). Misalnya kita mengharapkan selama 10' ada 5 (lima) pertanyaan dari siswa. Ternyata yang muncul hanya dua pertanyaan pada setiap perlakuan.

Perhitungan persentase pada perlakuan I, sebagai berikut $=$ Perilaku yang muncul $\quad$ x $100=$ Perilaku yang diharapkan

$$
\frac{2}{5} \times 100=40 \%
$$

Berdasarkan instrumen di atas, perlakuan diakhiri, bilamana sudah menampakkan peningkatan frekuensi perilaku (siswa mengajukan atau 
menanggapi pertanyaan dari materi yang dibahas) dari setiap perlakuan.

Untuk mengetahui adanya peningkatan perilaku bertanya atau menanggapi pertanyaan, dibuatlah suatu grafik berdasarkan hasil setiap 10', misalnya perlakuan I, ada dua pertanyaan muncul $40 \%$, perlakuan II ada dua pertanyaan yang diajukan dan satu menjawab pertanyaan, 60\%, dan perlakuan ke-III, ada dua pertanyaan muncul dan dua menjawab pertanyaan, $80 \%$.

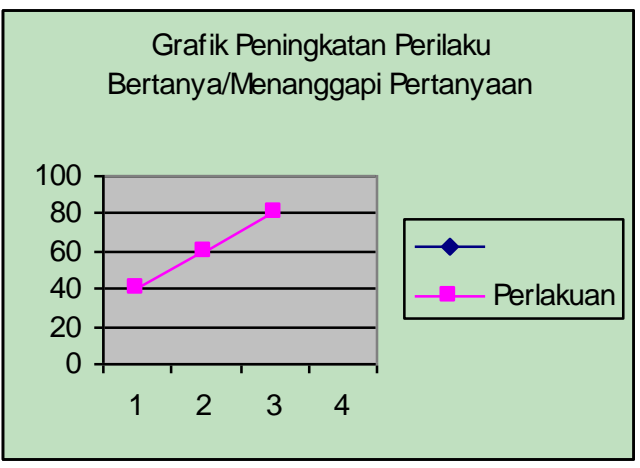

5)
Kedua, pencatatan dengan menggunakan sampling waktu. Pada model ini siswa diminta untuk mencatat berapa lama perilaku tersebut muncul pada bentuk format yang telah disediakan. Bilamana dalam waktu yang ditentukan (5'), perilaku yang diinginkan belum muncul, maka waktu diperpanjang lima menit berikutnya, demikian seterusnya sampai perilaku tersebut muncul.

Instrumen Pencatatan berdasarkan Sampling Waktu

Nama : Hari, tgl :

Kelas :

\section{Contoh Perilaku Target:}

\section{Mengajukan/Menanggapi Pertanyaan} Petunjuk!

1) Siapkan timer/jam

2) Setel per 5' (selama 40')

3) Mulai bekerja

4) Jika bel berbunyi pertanda waktu habis, apakah pada saat itu Anda sedang mengajukan/menanggapi pertanyaan? Jika ya, tulis " + " dalam kotak, dan jika tidak, tulis “ - " .

\begin{tabular}{|c|c|c|c|c|c|c|c|c|c|}
\hline \multirow{2}{*}{ Perlakuan } & \multicolumn{8}{|c|}{ Waktu (40') } \\
\cline { 2 - 12 } & $5^{\prime}$ & $5^{\prime}$ & $5^{\prime}$ & $5^{\prime}$ & $5^{\prime}$ & $5^{\prime}$ & $5^{\prime}$ & $5^{\prime}$ & \\
\hline I & + & - & - & - & + & - & - & - & \\
\hline II & & + & - & + & - & - & - & - & \\
\hline III & & + & + & - & - & - & - & - & \\
\hline
\end{tabular}

Untuk mengevaluasi program ini, penghitungannya adalah berapa waktu yang diperlukan untuk mengajukan atau menanggapi pertanyaan. Misalnya pada perlakuan I, selama 40', waktu terpendek pertanyaan muncul pada 5' pertama, sedangkan waktu terpanjang pada 5' kelima. Perlakuan ke-II, waktu terpendek pertanyaan muncul pada 5' kedua, sedangkan waktu terpanjang pada 5' keempat, dan pada perlakuan ke- III , waktu terpendek pertanyaan muncul pada 5' kedua, sedangkan waktu terpanjang pada 5' ke empat.

Perhitungan persentase waktu yang diperlukan, untuk mengajukan 
pertanyaan pada perlakuan I, dengan rumus sebagai berikut $=$

Perilaku muncul dlm waktu terpendek Perilaku muncul dlm waktu terpanjang

$$
\begin{aligned}
& \text { Perlakuan I }=\frac{5}{25} \times 100 \%=20 \% \\
& \text { Perlakuan II }=\frac{10}{20} \times 100 \%=50 \% \\
& \text { Perlakuan III }=\frac{10}{15} \quad \times 100 \%=66,6 \%
\end{aligned}
$$

Berdasarkan instrumen di atas, perlakuan diakhiri, bilamana sudah menampakkan peningkatan perilaku dalam waktu yang relatif pendek (singkat) setiap perlakuan. Untuk mengetahui adanya peningkatan perilaku bertanya atau menanggapi pertanyaan , dibuatlah suatu grafik berdasarkan sampel waktu, misalnya perlakuan I, muncul pertanyaan pada waktu yang relatif pendek (5'), perlakuan II, pertanyaan muncul pada $15^{\prime}$ berikutnya.

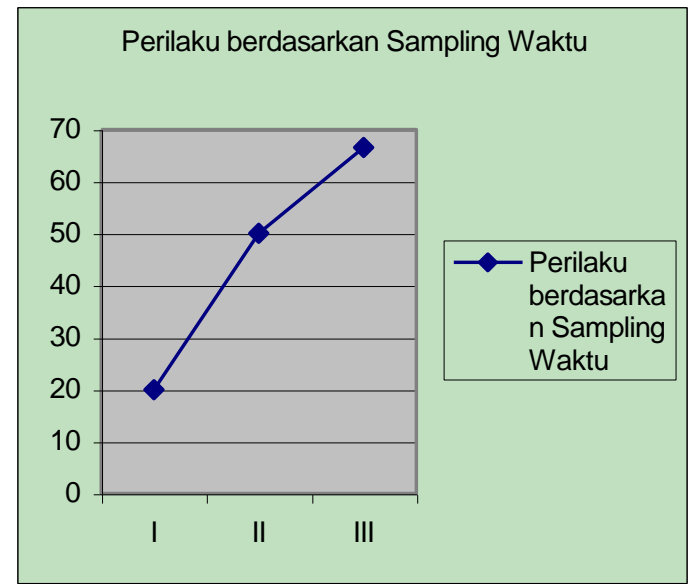

Model yang ketiga, adalah pencatatan dengan menggunakan dasar hasil permanen. Pada model ini siswa diminta menghitung dan mencatat jumlah tugas yang telah berhasil mereka selesaikan pada suatu waktu tertentu. x pagda model ini siswa didorong tidak saja untuk lebih perhatian pada segi jumlahnya tetapi juga harus memperhatikan segi kualitasnya.

Instrumen Pencatatan berdasarkan Hasil Permanen

Nama : Hari, tgl. :

Kelas :

Contoh Perilaku Target:

\section{Petunjuk!}

1) Isilah titik-titik sesuai yang dikehendaki pada judul kolom

2) Waktu yang diperlukan 15 ,

3) Selamat bekerja 


\begin{tabular}{|c|c|c|c|c|c|}
\hline \multirow{3}{*}{ Perlakuan } & \multirow{3}{*}{ Bid. Studi } & \multirow{2}{*}{\multicolumn{2}{|c|}{ Nomor }} & \multicolumn{2}{|c|}{ Jumlah Soal } \\
\hline & & & & \multirow{2}{*}{$\begin{array}{c}\text { Yang } \\
\text { diselesaikan }\end{array}$} & \multirow{2}{*}{$\begin{array}{c}\text { Jwbn } \\
\text { yang Benar }\end{array}$} \\
\hline & & Halaman & Soal & & \\
\hline I & & $\ldots$ & $\ldots$ & $\ldots$ &. \\
\hline II & ............. & ............. & ......... & .............. & ......... \\
\hline III & & & & & \\
\hline
\end{tabular}

Untuk mengevaluasi program ini, penghitungannya adalah berapa nomor soal yang telah diselesaikan, berapa yang benar dan berapa yang salah, dalam waktu yang ditentukan (per 15 menit-an). Kita mengharapkan selama waktu 15', semua soal (5 soal) dapat diselesaikan, dan jawabannya benar.

Perhitungan persentasenya perilaku sebagai berikut:

Jumlah soal yang benar $\mathrm{X} 100 \%$

Jumlah keseluruhan soal

Perilaku Menjawab Soal dengan Benar

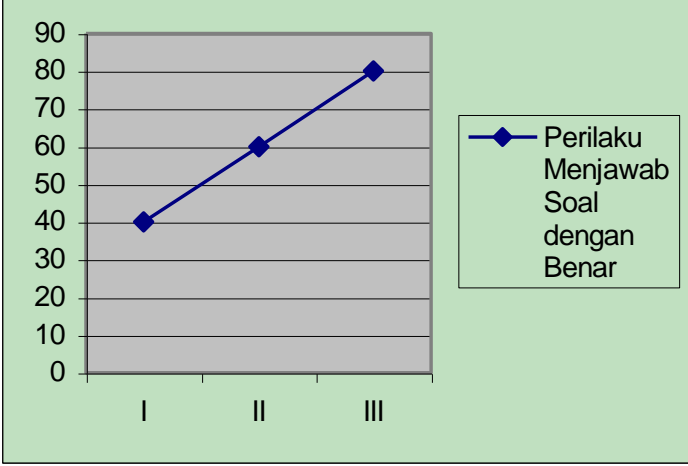

Contoh:

Perlakuan I,

dua soal diselesaikan dengan benar $=2 \quad$ Teknik Self-Evaluation untuk

\section{$5 \times 1$ Meningkatkan Perilaku Belajar}

Self-evaluation (menilai diri

Perlakuan II,

tiga soal diselesaikan dengan benar $=\underline{3}$ sendiri) sebagai proses mengevaluasi

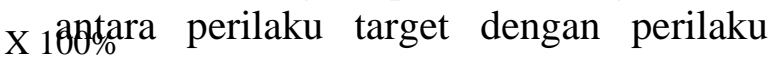
yang diinginkan, untuk kemudian dibandingkan, adakah perbedaan antara

Perlakuan III, empat soal diselesaikan dengan benar $=4$ kedua perilaku tersebut. Jika antara

Berdasarkan instrumen di atas, perlakuan diakhiri, bilamana sudah menampakkan peningkatan jumlah menjawab benar dari soal yang diberikan dalam waktu yang ditentukan pada setiap perlakuan. xpmodaku target dengan yang diinginkan sama, artinya tercapai, maka dianggap tidak bermasalah dan tentu saja memuaskan siswa. Tetapi jika antara perilaku target dengan perilaku yang diinginkan terdapat perbedaan atau kesenjangan, maka perilaku tersebut dianggap bermasalah dan tentu mengecewakan siswa, dan untuk itu perlu ditindaklanjuti dengan langkah selanjutnya, yaitu self-reinforcement.

Pada tahap ini siswa harus membuat perbandingan antara apa yang telah dikerjakan (dicatat) sebagai perilaku target, dan perilaku apa yang seharusnya diinginkan. Catatan data hasil pengamatan tingkah laku ini harus dibuat secara teratur, sebab catatan yang teratur merupakan hal yang sangat penting untuk dijadikan sebagai bahan evaluasi untuk 
melihat efektivitas dan efisiensi program analisis dan pengubahan tingkah laku. Dari hasil evaluasi tersebut dapat diketahui berhasil tidaknya suatu program yang telah diterapkan. Bila hasil evaluasi terhadap program yang diterapkan tidak berhasil, maka perlu ditinjau kembali, sudah tepatkah tingkah laku target yang dipilih, reinforcer yang dipilih, dan bagaimana prosedur penggunaannya. Sebagai contoh. Santi telah berjanji pada diri sendiri, apabila ia berhasil menyelesaikan tugas dengan benar, ia akan refreshing jalan-jalan ke Mall. Begitu ia dapat memenuhi target tersebut, ternyata ia lupa untuk memberikan reinforcer bagi dirinya, karena ia harus menyelesaikan tugas lain yang belum terselesaikan.

Instrumen Self-valuation untuk Meningkatkan Perilaku mengerjakan Tugas

Nama : Hari, tgl.

Kelas:...

Waktu:

40

menit

\begin{tabular}{|c|c|c|c|c|}
\hline \multirow{2}{*}{ Perlakuan } & \multicolumn{2}{|c|}{ Perilaku } & \multirow{2}{*}{ Hasil } & \multirow{2}{*}{ Ket. } \\
\hline & Target & Yang diharapkan & & \\
\hline I & $\begin{array}{l}\text { Mengerjakan } \\
5 \text { tugas } \\
\text { dengan benar }\end{array}$ & $\begin{array}{l}\text { Tugas yang } \\
\text { dikerjakan mini- } \\
\text { mal } 75 \% \text { benar }\end{array}$ & $\begin{array}{l}\text { Memuaskan } \\
\text { / Tidak }\end{array}$ & \multirow{3}{*}{$\begin{array}{l}\text { Kreteria: } \\
\text { Memuaskan, } \\
\text { jika tugas } \\
\text { dikerjakan } \\
\text { minimal } 75 \% \\
\text { benar, dan } \\
\text { sebaliknya. }\end{array}$} \\
\hline II & $\cdots$ & n....... & $\cdots \cdots \cdots$ & \\
\hline III & & & & \\
\hline
\end{tabular}

Untuk mengevaluasi program ini, penghitungannya adalah apakah perilaku yang diinginkan sudah tercapai/belum. Perhitungannya persentasenya sebagai berikut:

Jumlah Jawaban benar $\begin{array}{lll}\text { Jumlah seharusnya benar } & X & 100 \%\end{array}$

Berdasarkan instrumen di atas, perlakuan diakhiri, bilamana sudah menampakkan peningkatan jumlah menjawab benar dari soal yang diberikan dalam waktu yang ditentukan pada setiap perlakuan. Dengan demikian hasilnya dapat digrafikkan.

\section{Teknik Self-Reinforcement untuk Meningkatkan Perilaku Belajar Siswa di SMA}

Siswa tentunya diharapkan dapat mengatur dan mengarahkan dirinya sendiri, antara lain dengan memberikan reinforcement terhadap dirinya sendiri.
Tetapi dalam kenyataan, hal ini tidaklah mudah untuk dilakukan. Kesulitan untuk memberikan reinforcement ini dapat diatasi dengan meminta bantuan orang lain yang dalam hal ini guru untuk memegang reinforcer.

Yang perlu diketahui adalah bahwa reinforcer yang baik adalah yang wajar dan itu muncul secara instrinsik (dari dalam diri individu sendiri). Seperti rasa bangga akan keberhasilan usaha yang dilakukannya sendiri, mempertebal rasa percaya diri, karena mampu menyelesaikan pekerjaan yang dianggap sangat sulit, atau tersenyum puas melihat hasil kerjanya.

Untuk mengajarkan teknik selfreinforcement kepada siswa, guru harus menyadari hal-hal yang dapat mempengaruhi kesuksesan program, artinya guru harus tahu dengan pasti reinforcer-reinforcer mana yang dapat mendorong tercapainya tujuan program. Guru perlu menginformasikan kepada siswa untuk mengerjakan sesuatu dengan 
baik, dimana bila siswa mengerjakan tugasnya dengan baik akan dapat hadiah dan sebaliknya apabila siswa tidak dapat melakukan tugasnya dengan baik maka ia akan mendapatkan sedikit bayaran (hadiah) atau bahkan tidak mendapatkan bayaran (hadiah) sama sekali. Siswa diberi kebebasan untuk menentukan sendiri kriteria yang digunakan untuk menentukan sendiri apakah ia layak mendapat reinforcer atau tidak, siswa diberi kebebasan untuk menentukan bentuk dan berapa banyak reinforcer tersebut diberikan kepada dirinya sendiri.

Instrumen Self-Reinforcement untuk Meningkatkan Motivasi Bertanya Menanggapi pertanyaan pada Pembelajaran Siswa di SMA

Nama : Hari, tgl.:

Kelas:

\begin{tabular}{|c|c|c|c|c|}
\hline Perilaku Target & $\begin{array}{c}\text { Perilaku } \\
\text { yang } \\
\text { Diinginkan }\end{array}$ & Keberhasilan & Reinforcement & Ket. \\
\hline & & & & $\begin{array}{l}\text { Keberhasil } \\
\text {-an: } \\
\text { berha- } \\
\text { sil/tidak } \\
\text { Reinforce- } \\
\text { ment: } \\
\text { ada/tidak }\end{array}$ \\
\hline
\end{tabular}

Untuk mengevaluasi program ini, penghitungannya adalah apakah perilaku yang diinginkan sudah tercapai/belum. Bila sudah tercapai diberi reinforcement/ tidak. Berdasarkan instrumen di atas, perlakuan diakhiri, bilamana sudah menampakkan peningkatan perilaku yang diinginkan dan setiap perilaku yang diinginkan muncul diberi reinforcement. Contoh:

Jika saya mengajukan pertanyaan pada saat pembelajaran berlangsung, maka saya akan mengucapkan kata "Yes". Atau, saya akan katakan "Asyik saya berhasil", bila saya berani mengajukan pertanyaan pada saat pembelajaran di kelas, dan lain-lain.

\section{Daftar Rujukan}

Abdullah, A.E., (Ed.) 1990. Pokok-pokok Layanan Bimbingan Belajar, Ujung Pandang: FIP-IKIP

Alberto, P.A. \& Troutman, A. C., 2001 Applied Behavior Analysis for Teacher Fourth Edition New Jersey: Prentice Hall, Inc.
Corey, G., 2000. Theory and Practice of Counceling and Psychotherapy. California; Brooks/Cole Puplishing Company.

Cormier, W. H. \& Cormier, L.S 2002. Interviewing Strategies of Helpers. Foundamental Skill and Cognitive Behavioral Interventions. Second Edition, Monterey, California: Brokks/Cole publishing company.

Dick, W., \& Carey, L., 1990. The Systemetic Design of Instruction. Third Edition, USA: Harper Collins Publishers.

Kanfer, F.H. \& Goldstein. 1982. Helving People Change A. texbook of Methods. Scond Edition. New York: Pergamon Press.

Schloss, P.J. \& Smith, M.A. 1994. Applied Behavior Analisys in the Classrooom: Boston: Allyn and Bacon. 
Shertzer, B. \& Stone, S. C. 2003. Foundamentals of Gutdance. Fourth Edition. Boston: Houghton Mifflin Company.

Surya, dkk. 2002. Kapita Selekta Kependidikan SMA. Jakarta: Universitas Terbuka 
